\title{
A narrativa de histórias de vida como recurso metodológico na pesquisa em psicologia
}

\author{
Ronaldo Adriano Alves dos Santos ${ }^{1}$ \\ Danielly Christina de Souza Mezzari ${ }^{2}$ \\ Fernando Silva Teixeira-Filho 3 \\ Universidade Estadual Paulista Júlio de Mesquita Filho
}

Resumo: A pesquisa qualitativa em psicologia tem a ver com um reconhecimento de que a vida, a subjetividade e as experiências sociais são, dentre outras coisas, formações discursivas. Dentro desta perspectiva, a narrativa de histórias de vida assume a parcialidade da produção de conhecimento como inerente ao desenvolvimento de uma pesquisa e pode ser pensada como uma alternativa às metodologias hegemônicas assentadas em bases positivistas. Neste processo de questionamento e transformação, os feminismos nos ajudam a problematizar alguns pressupostos antes tidos como essenciais para o fazer científico, tais como a neutralidade, as distinções dicotômicas sujeito/objeto, natureza/cultura, etc. A pesquisa narrativa assume a experiência como inerente à produção de conhecimento e abre a possibilidade de questionamento a um saber que se faria independente dos sujeitos que o produzem.

Palavras-chave: pesquisa em psicologia; narrativas de histórias de vida; feminismos.

\footnotetext{
${ }^{1}$ Doutorando no Programa Psicologia e Sociedade da UNESP. Mestre em Psicologia e Sociedade pela UNESP. Pósgraduado em Filosofia Política e do Direito, pela UNIOESTE. Graduado em Psicologia pela Pontifícia Universidade Católica do Paraná Campus Toledo. É docente do Curso de Psicologia da Pontifícia Universidade Católica do Paraná.

${ }^{2}$ Graduada em Psicologia pela Universidade Estadual do Centro Oeste (UNICENTRO/PR). Mestra em Psicologia Social pela Universidade Estadual Paulista Júlio de Mesquita Filho, Faculdade de Ciências e Letras. Doutoranda em Psicologia Social pela mesma Universidade e integrante do grupo de pesquisa Psicuqueer: Coletivo Psicologias e Culturas Queer.

3 Licenciado e formado em Psicologia pela Universidade Paulista (1989); Mestre (1993) e Doutor (2000) em Psicologia (Psicologia Clínica) pela Pontifícia Universidade Católica de São Paulo e Livre-Docente (2013) em Psicologia Clínica pela Universidade Estadual Paulista (UNESP), Faculdade de Ciências e Letras Júlio de Mesquita Filho. Atualmente é professor adjunto (nível I) na Universidade Estadual Paulista, em Assis, SP, atuando na graduação e na pós-graduação.
} 


\title{
The narrative of life stories as a methodological resource in research in psychology
}

\begin{abstract}
Qualitative research in psychology has to do with a recognition that life, subjectivity and social experiences are, among other things, discursive formations. Within this perspective, the narrative of life histories assumes the bias of the production of knowledge as inherent to the development of a research and can be thought of as an alternative to hegemonic methodologies based on positivist bases. In this process of questioning and transformation, feminisms help us to problematize some assumptions previously considered essential for scientific doing, such as neutrality, subject / object dichotomous distinctions, nature / culture, and so on. Narrative research takes experience as inherent in the production of knowledge and opens the possibility of questioning to a knowledge that would be independent of the subjects that produce it.
\end{abstract}

Keywords: research in psychology; narratives of life stories; feminisms.

\section{La narrativa de historia de vida como recurso metodológico en la investigación psicológica}

\begin{abstract}
Resumen: La investigación cualitativa en psicología tiene que ver con el reconocimento de que la vida, la subjetividad y las experiencias sociales son, entre otras cosas, formaciones discursivas.En esta perspectiva, la narrativa de historias de vida asume la parcialidad de la producción de conocimiento como inherente al desarrollo de la investigación y puede ser concebida como una alternativa a las metodologías hegemónicas basadas en bases positivistas. En este proceso de cuestionamiento y transformación, los feminismos nos ayudan a problematizar algunos supuestos previamente considerados esenciales para la práctica científica, como la neutralidad, las distinciones dicotómicas sujeto/objeto, naturaleza/cultura, etc. La investigación narrativa toma la experiencia como inherente a la producción de conocimiento y abre la posibilidad de cuestionar conocimientos que serían independientes de los sujetos que lo producen.
\end{abstract}

Palabras clave: investigación en psicología; narrativas de historias de vida; feminismos. 
$\mathrm{N}$ presente trabalho pretendemos abordar a narrativa de histórias de vida como método potentes na construção de saberes e fazeres nas e das Psicologias. Para promover esse debate é importante explicitar a necessidade de estabelecermos uma crítica aos modos que, historicamente, algumas Psicologias assentam suas produções teóricas e práticas dentro de um paradigma moderno de ciência. Isso ocorre, pois, é comumente aceito que as Psicologias ascendem ao status de ciência quando, em 1879, Wundt inaugura o laboratório de psicologia experimental em Leipzig, na Alemanha. Muito embora já houvessem escritos psicológicos anteriores ao advento do laboratório de Wundt, foi justamente o caráter experimental dessa Psicologia nascente que possibilitou à época sua "ascensão" ao território da cientificidade positivista.

Sabe-se que a ciência positivista asseverou a existência de uma realidade objetiva a ser revelada por meio da pesquisa e produção acadêmica a fim de construir conhecimentos capazes de desvelar o funcionamento dos fenômenos e predizer sua ocorrência futura. Tomando a exterioridade como dado objetivo, a participação e intervenção da subjetividade dus pesquisadoris (e dus participantis) 4 no processo de pesquisa é vista como ruído a ser controlado e na medida do possível silenciado, evitando assim "contaminações" ou enviesamentos dos dados e resultados da pesquisa. Isso ocorre pois, a pretensa imparcialidade dus pesquisadoris e o controle das variáveis é percebida como condição sine qua non da construção de uma análise objetiva da realidade, livre de preconceitos e juízos de valor.

Segundo Oliveira e Amâncio (2006) é a partir da crise do paradigma positivista entre os anos 60 e 70 do século XX que se evidencia, de forma mais acentuada, que tais pressupostos, aliados ao enviesamento androcêntrico, racista, sexista, machista e LGBTFóbico e cisheteronormativo da ciência, são limitados ou mesmo incapazes de dar conta da complexidade dos fenômenos sociais e subjetivos. Dessa constatação surge a necessidade da articulação entre as ciências sociais e humanas (e nelas as Psicologias) e a política, para assim construir novos modos de produzir conhecimento sobre a realidade social (NEVES, 2012).

$\mathrm{E}$, por fim, com esta mudança paradigmática, vieram também novas questões de pesquisa. Já não bastava apenas saber a quantidade de ocorrências de um fenômeno, mas também, os modos de sua produção, suas relações com os processos de subjetivação e suas interações no contexto de ocorrência. Assim, por exemplo, passou a ser importante saber não apenas o tipo e frequência de ataques LGBTfóbicos sofridos pela população LGBTQIA+, mas, sobretudo, seus efeitos a curto, médio e longo prazo na vida destas pessoas. Com o advento do flagelo da AIDS, nos idos anos 80, tornou-se importante saber sobre a qualidade dos cuidados, as redes de proteção e atenção que os gays vitimados pela doença desenvolveram para se apoiarem. Nos inúmeros casos de violência contra a criança, adolescentes e mulheres, tornou-se fundamental conhecer as dinâmicas

\footnotetext{
${ }_{4}^{4}$ Adotamos neste trabalho o uso de uma linguagem não binária proposta por Lau (2017). Sendo assim os adjetivos e substantivos terão suas vogais generificadas "a" (para indicar o feminino) e "o" (para indicar o masculino) substituídos pela vogal "e". No caso de palavras em que o plural é costumeiramente considerado masculino faremos a substituição do "es" pelo "is" (exemplo: "pesquisadores" será grafado como "pesquisadoris"). As preposições "do(s)" e "da(s)" serão substituídas por "du(s)". Os artigos definidos "a(s)" e "o(s)" serão substituídos por "le(s)", já os artigos indefinidos "um/uns" e "uma(s)" serão substituídos por "umes(s)". Pronomes possessivos "meu(s)" e "minha(s)" serão substituídos por "mi(s)", "su(s)". O objetivo dessa decisão é produzir uma alternativa que viabilize a produção textual/acadêmica sem marcar de forma binária os conteúdos e as vozes que constituem e configuram o texto, produzindo assim uma linguagem que vai além da binaridade de gêneros.
} 
de interações familiares, sobretudo por serem a maioria dos agressores advindos da própria família da vítima. No debate sobre o racismo emerge também a necessidade de discutir a experiência e os modos por meio dos quais o racismo estrutura as relações sociais e econômicas e igualmente as subjetividades e as vivências cotidianas individuais e coletivas, (re)criando e (re)significando espaços e paisagens concretas e simbolicamente racializadas. A emergência dessas novas questões demanda a busca pelos significados construídos para estes fenômenos e não apenas conhecer suas incidências (FONTE, 2006). É nessa esteira que a pesquisa qualitativa, e nela as pesquisas e análises narrativas, ganham espaço e impulso.

\section{Narrativas de histórias de vida: Método e Objeto}

Construir uma pesquisa qualitativa em Psicologia é também uma forma de reconhecer que a vida, as subjetividades e a experiência são construções discursivas (SCOTT, 1998) que fluem abertamente, como um rio margeado por determinados contextos espaço-temporais que comprimem e impõem certos ritmos aos fluxos vividos. Nesse sentido, somos levados a reconhecer que o próprio conhecimento da realidade também se constitui (social e historicamente) e se circunscreve em determinados contextos espaço-temporais. Essa percepção torna impossível qualquer processo de universalização e consequentemente nos leva a reconhecer que todos os conhecimentos produzidos configuram-se como vislumbres parciais do mundo (NEVES, 2012).

Reconhecendo essa parcialidade da produção do conhecimento, a narrativa de histórias de vida surge como uma potente alternativa às metodologias estanques de base positivista. Teixeira Filho (2013) nos explica que a pesquisa narrativa não é uma teoria aplicada que se propõe a explicar algo ou a projetar uma noção de inteligibilidade sobre um determinado fenômeno. Ela procura, ao invés disso, "analisar o modo como interpretamos as coisas, as ideologias que embasam nossas opiniões, os regimes de controle que organizam os significados que damos às coisas, que lhes dão inteligibilidade" (TEIXEIRA-FILHO, 2013: 91). Nesse sentido, a pesquisa narrativa recorre a (re)produção de histórias sobre práticas de vida e sobre o modo como essas práticas atravessam os processos de subjetivação.

Destarte, pensar as narrativas de história de vida como base para a construção do conhecimento torna imprescindível a percepção de que elas se constituem como "método-processo de investigação", pois como afirmam Biglia e BonetMartí (2009) a utilização de narrativas de história de vida se configuram como um novo método e objeto de análise discursiva:

\footnotetext{
Na narrativa a preocupação é [...] construir significados, estabelecer relações e refletir sobre os fatos previamente narrados nas estórias. A estória se torna, pois, objeto e método de pesquisa. Objeto porque é nela que os esforços se concentram para se chegar a uma compreensão mais concreta da experiência. É, também, método, porque é pela narração que os significados são construídos. (TELLES, 1999: 89)
}

Esse método e objeto nos possibilita o acesso e a (re)escritura e tecitura de paisagens subjetivas e sociais, servindo de plataforma para repensarmos as antigas formas de validação positivista do conhecimento. As pesquisas e análises narrativas, podem ser consideradas, segundo Passos e Barros (2009), como uma forma de pesquisa capaz de incluir a dimensão subjetiva inerente ao encontro entre pesquisadoris e participantis da pesquisa. Nesse encontro o acesso à dimensão subjetiva se dá através da escuta das memórias narradas sobre as his- 
tórias de vida dus participantis da pesquisa (TOLEDO, 2013). Assim, a pesquisa narrativa, com foco na história de vida, é uma forma de produção de conhecimento que tem como característica fundamental a atenção dada ao vínculo criado entre pesquisadoris e participantis da pesquisa (SILVA et. al., 2007) ou ainda, nas pesquisas em psicologia clínica, entre analista e analisando (GRANATO, CORBERT, AIELLO-VAISBERG, 2011). Desse modo, a narrativa de histórias de vida constitui-se como um processo colaborativo de (re)construção conjunta (propiciada pela interação, relação e experiência compartilhada entre pesquisadoris e participantis) de uma narrativa (NEVES, 2012; PAIVA, 2008).

\begin{abstract}
O conhecimento da realidade, que é assim sempre parcial e subjectivo, depende do acesso às experiências individuais e colectivas, sendo este acesso viabilizado pela linguagem e influenciado pela interacção entre investigadores/as e investigados/as. Idealmente, o modo como se acede às experiências, deve caracterizar-se pela não estruturação, já que esta facilita a expressão não induzida da linguagem. (NEVES, 2012: 7)
\end{abstract}

Esse reconhecimento exige a percepção de que todo conhecimento é localizado e atravessado pelos marcadores sociais de diferença e pelas experiências vividas pelus pesquisadoris e participantis das pesquisas. Sendo assim, pensar e produzir conhecimento a partir de uma lógica de localização não é uma negação das possibilidades de produção de práticas e saberes dos indivíduos, antes disso é reconhecer as parcialidades e os efeitos das subjetividades dus pesquisadoris e dus participantis da pesquisa evidenciando a não existência de uma uniformidade e generalidade nas e das produções científicas.

Colabora com essa discussão as problematizações apresentadas por Haraway (1995) quando ela discute a noção de objetividade afirmando que esta só pode se fazer presente quando temos como ponto de partida a parcialidade de nossas posições. Para a autora a objetividade tem a ver com uma configuração específica que se produz no parcial e no localizado, o que permite a responsabilização pelas próprias práticas. Assim, o posicionamento dus pesquisadores e dus participantis passa a ser concebido como uma prática fundamental para o fazer científico e o que conta ou não como conhecimento racional, como alega Haraway, passa a ser legitimado ética e politicamente e não tendo a partir de uma suposta referência a uma realidade independente dos sujeitos.

Nesse sentido, podemos dizer que toda produção de saber é localizada e possui um ponto de partida que passa sempre pela experiência e pelo desejo de quem a produz. A proposta de conhecimentos situados apresentada por Haraway (1995) vai nesta direção. A pesquisadora nos explica que a produção do conhecimento se dá por meio de vinculações que são sempre parciais e encarnadas. Portanto, reconhecer que não podemos assumir uma visão totalmente abrangente, totalizadora, de um fenômeno nos conduz à necessidade de criarmos redes, conexões e alianças.

Essa constatação implica percebermos que em toda produção do conhecimento, em especial nas pesquisas e análises narrativas, as/os pesquisadora/es desempenham um papel inevitavelmente implicado ética, estética e politicamente (PASSOS e BARROS, 2009; TOLEDO, 2013). Isso se dá, pois, a utilização dessa metodologia tanto de pesquisa quanto de intervenção pressupõe necessariamente a existência de um compromisso, entre pesquisadoris e participantis, com a transformação social e com a militância em prol da emancipação humana (NEVES e NOGUEIRA, 2003).

Nessa perspectiva poderíamos dizer que, em uma pesquisa narrativa,

'tudo é político', indicando que o caso individual é índice singular de situações que, problematizadas, mostram-se como ethos político, com ramificações do caso indivi- 
dual no plano imediatamente político. A fronteira que separa o "caso individual" do plano político mostra-se bem mais uma franja, zona de indiscernibilidade, do que marca de separação entre um (o caso) e o de qualquer um (o político). (PASSOS e BARROS, 2009: 167)

Considerando esse aspecto político da pesquisa não podemos perder de vista que toda narrativa de vida aborda um conjunto de experiências que é sempre (e ao mesmo tempo) individual e coletiva. Falamos dessa ambivalência das experiências pois, partimos do pressuposto de que a "experiência é um acontecimento linguístico - e - uma vez que o discurso é por definição compartilhado, a experiência é coletiva, bem como individual" (SCOTT, 1998: 320). Nessa processualidade da experiência (individual e coletiva) que se narra resulta seu caráter eminentemente político, pois, ela pode servir à (re)afirmação do conhecido ou à contestação daquilo que é tido como certo e óbvio.

Colabora com essa discussão a asserções de Teixeira Filho (2013), quando afirma que toda narrativa é sempre coletiva, visto que não é fruto simplesmente de um esforço individual, mas sim de uma produção coletiva, de encontros, relações e interações nas quais a pessoa que narra se inseriu (TEIXEIRA-FILHO, 2013). Portanto, há sempre uma negociação das lembranças implicando em uma reorganização das próprias narrativas. Cabe aus pesquisadoris, nesta perspectiva, procurar se inserir também nas narrativas não contadas ou jamais lembradas.

Assim, ao ambicionarmos a construção de pesquisas que possam servir como um instrumento político de transformação social, reconhecemos a linguagem como constituinte das relações sociais e, portanto, espaço privilegiado de produção de saberes e de luta. Esse reconhecimento se traduz na busca de construir pesquisas calcadas em pistas metodológicas capazes de, a partir da (re)construção de narrativa de histórias de vida, transformar histórias individuais/coletivas em uma importante e "poderosa fonte de análise social" (NEVES, 2012: 9). Pois como afirma Passos e Barros (2009: 167-8) em uma narrativa "tudo adquire valor coletivo [...] e institui-se como agenciamento coletivo de enunciação [...]. Mesmo quando vivido, enunciado, protagonizado, emitido por uma singularidade, a narrativa não remete a um sujeito".

É nesse sentido que Paiva (2008) afirma que a pesquisa narrativa objetiva explicitar os mecanismos que operam na produção de um sentido particular e retirar daí as implicações e ressonâncias que esse sentido tem para a existência humana. Para a autora a pesquisa narrativa não se constitui como uma simples enunciação de fatos e eventos vividos, ela trata de uma (re)construção narrada de situações vividas e que fazem parte da biografia de participante da pesquisa e que a partir de uma avaliação emocional e social é transmutada em experiência que pode ser socialmente compartilhada.

Compreendemos assim que a experiência não pode ser dissociada da produção de conhecimento (GONÇALVES, 2002). Porém Scott (1998) nos adverte de que a experiência não pode ser tomada como um dado pronto a ser desvelado pelus pesquisadoris, antes disso ela necessita ser percebida e pensada à luz dos processos sociais, históricos e discursivos que as constituem. Essa percepção é importante, pois, como afirma a autora, é necessário historicizarmos a experiência e as identidades que ela produz, uma vez que "não são os indivíduos que têm experiência, mas sim os sujeitos que são constituídos pela experiência. Experiência nesta definição torna-se [...] o que procuramos explicar, sobre o que o conhecimento é apresentado" (SCOTT, 1998: 304).

Neste sentido, o próprio processo vital tem a ver com construir ativamente conhecimento e não simplesmente armazená-lo. Desse modo, consideramos 
perigoso partir do pressuposto de que as histórias são coletadas como se já estivessem prontas e fossem simplesmente transmitidas de uma pessoa para outra. Benjamin (1994) já afirma que, ao contrário da informação, a narrativa pede uma experiência daquilo que se conta. Nesse sentido, o sujeito que conta uma história se preenche dela e a preenche de si e les ouvintis, quando forem narrar essa mesma história, inevitavelmente a impregnarão de suas próprias experiências também e ela, por consequência, já não será mais a mesma.

Para a execução desse processo de (re) construção narrativa de histórias de vida, a pesquisa narrativa pode lançar mão de uma série de técnicas e procedimentos tais como: entrevistas, questionários, grupos focais, introspecção, artefatos, observação participante, diários, autobiografias, gravação de narrativas orais, narrativas escritas, notas de campo, produções culturais e documentos (PAIVA, 2008; PASSOS e BARROS, 2009; BIGLIA e BONET-MARTÍ, 2009; NEVES, 2012). A utilização dessas diferentes técnicas e procedimentos é vantajosa pois favorece tanto a aproximação quanto a discussão da realidade social e das experiências subjetivas dus participantis da pesquisa. Processo que possibilita que les pesquisadoris acessem os "[...] elementos simbólicos que as constituem, especialmente a partir da descodificação de códigos linguísticos e performativos" (NEVES, 2012:5).

Dentre essas diversas técnicas e procedimentos as entrevistas (por possibilitarem o encontro direto entre pesquisadoris e participantis e o consequente intercâmbio discursivo e subjetivo) despontam como procedimento especialmente valorizado (PAIVA, 2008; BIGLIA e BONET-MARTÍ, 2009; NEVES, 2012). A entrevista é percebida como um processo de negociação e construção compartilhada de sentidos a partir do diálogo e interação produzidos no encontro entre pesquisadoris e participantis em um determinado contexto específico (BIGLIA e BONET-MARTÍ, 2009). Ao comentar os trabalhos desenvolvidos por Oakley e Monroe-Baillargeon, Neves (2012:6) afirma que as entrevistas exigem "uma relação de abertura e de confiança entre os/as entrevistadores/as e os/as entrevistados/as" de modo a construir um espaço que valorize "as trocas, a colaboração e a interactividade" que segundo a autora formam a "base do processo de narração de histórias".

Neves (2012) destaca ainda que a pesquisa a partir da narrativa de histórias de vida nos possibilita acessar as experiências dus participantis da pesquisa dando especial atenção às suas idiossincrasias, permitindo assim que os discursos e experiências das "pessoas reais, contadas na primeira pessoa" sejam acessados e inseridos no seio do discurso acadêmico/científico. Esse acesso às experiências e às subjetividades através da fluidez produzida no encontro entre pesquisadoris e participantis são fatores extremamente potentes da e na construção da pesquisa narrativa. E reconhecendo essa potência e as idiossincrasias inerentes a esse processo Biglia e Bonet-Martí (2009) afirmam que ao invés de explicar os resultados da pesquisa podemos nos debruçar sobre a montagem e a contação de um conto como parte fundamental e central da pesquisa. É nesse sentido que a autora afirma a possibilidade e a potência da narrativa de história de vida de (re)construir sentidos através da linguagem, permitindo assim, muito além da produção de um conhecimento, o empoderamento das vozes daqueles que contam suas histórias.

Esse processo de iluminação e ressonância de vozes, que ocupam espaços social e historicamente silenciados, nos remete ao conceito de "literatura menor" cunhado por Deleuze e Guattari (1977) para afirmar a possibilidade de, por meio da pesquisa, construirmos "uma experiência narrativa minoritária". Para 
os filósofos franceses "uma literatura menor não pertence a uma língua menor, mas, antes, à língua que uma minoria constrói numa língua maior" (DELEUZE e GUATTARI 1977: 25). Nesse sentido, construir uma pesquisa a partir da narrativa de histórias de vida (língua de uma minoria) mostra-se como uma possibilidade de (re)construir e dar passagem a essa língua dentro do mundo acadêmico (língua maior) através de um posicionamento capaz de produzir interrogações, estranhamentos, abalos e fissuras naquilo "[...] que certa narrativa aceitaria como natural e regra, forçando a um descolamento do dito na busca das condições de sua produção" (PASSOS e BARROS, 2009: 164).

Araújo e colaboradores (2016: 592) reconhecem essa possibilidade de produzir ranhuras nos antigos modos de fazer e produzir ciência e ao comentarem a obra de Amado (2009) afirmam que tal perspectiva metodológica deve assentarse "no pressuposto de que narrar é reescrever e não descrever. [...] interpretar a narrativa experiencial não é descrever objetivamente o presente como um encadeamento causal de um passado, é subjetivá-lo para o projetar no futuro”.

Toda essa potência das narrativas de histórias de vida torna-se ainda mais evidente quando produzimos sua articulação às epistemes feministas. Essas epistemologias nos auxiliam a problematizar os modos hegemônicos de produção do conhecimento e das práticas sociais e servem como plataforma para arquitetarmos a construção de novos modos de produção de saberes, sociabilidades e subjetividades. E pensando nessas possibilidades buscamos a seguir tecer algumas discussões (também parciais) sobre os modos como concebemos a articulação entre as narrativas de história de vida e as epistemologias feministas.

\section{Narrativas de história de vida e feminismos}

Sandra Harding (1987) lançou há algum tempo um questionamento acerca do que distingue um método feminista. $\mathrm{O}$ que faz com que uma pesquisa seja feminista? É o fato de ser produzida por uma mulher? Ser sobre mulheres? Ter em suas referências bibliográficas centrais o nome de mulheres? Como podemos identificar um trabalho como sendo feminista? Para a autora, existem três características fundamentais que distinguem os estudos feministas. A primeira delas se refere à crítica à ciência social tradicional que parte da experiência dos homens para desenvolver suas análises. Quando pensamos na transformação de um fenômeno social em um problema a ser investigado, percebemos que não existe um problema se não há uma pessoa ou um grupo que o defina enquanto tal, ou seja, um problema é sempre um problema para alguém (HARDING, 1987). Uma proposta feminista, portanto, se preocupa em mostrar que as perguntas que são formuladas, inclusive as que nunca o são, determinam a pertinência e o alcance do nosso trabalho tanto quanto as repostas que encontrarmos.

Nesse sentido, e como segunda característica, a autora afirma que é próprio do feminismo estar a favor das mulheres. As perguntas que foram feitas sobre as mulheres sempre foram marcadas pelo desejo masculino de dominação, de controle e manipulação. Harding (1987) sublinha, no entanto, que é importante falar sobre a "experiência das mulheres", sempre no plural, tendo em vista que o masculino e o feminino são constituídos sempre dentro de uma classe, uma raça e uma cultura particulares. As perguntas que um grupo oprimido deseja que sejam respondidas quase nunca correspondem às demandas consideradas mais legítimas ou mais verdadeiras. Por fim, a terceira característica a qual a autora faz alusão se refere à relação entre pesquisadoris e participantis da pesquisa. 
Harding (1987) afirma que é preciso situar pesquisadoris e participantis no mesmo plano crítico. Se o estudo das mulheres não é algo novo, o é o estudo a partir de nossas próprias perspectivas e experiências. A autora advoga a necessidade de se explicitar o gênero, raça, classe dus investigadoris e como esta suspeita que esses atravessamentos influenciam no processo de investigação. Este esforço não tem o objetivo de se configurar enquanto uma espécie de bom comportamento, como assevera Harding (1987), mas sim de reconhecer que as crenças e lugares ocupados socialmente modelam nossas perspectivas.

Sendo assim, partimos do pressuposto de que precisamos desconfiar das verdades estabelecidas, bem como da pretensa objetividade do conhecimento científico. Haraway (1995) nos diz que os relativismos e as teorias totalizadoras são maneiras de se alegar estar em todo o lugar e, ao mesmo tempo, em nenhum. Esse processo e procedimento culmina, em última análise, em uma desresponsabilização e falta de avaliação crítica. Para a autora, precisamos começar a pensar a objetividade enquanto saberes localizados, pois é só no parcial e no localizado, em uma corporificação específica, que somos capazes de assumir a responsabilidade pelas nossas práticas. Haraway (1995) propõe que a responsabilidade feminista deve avançar não por dicotomias, mas sim por ressonância, por afinidades e não por identidades.

Haraway (1995), como já mencionado alhures, afirma que toda produção de saber é sempre encarnada e parcial. Ou seja, nossas experiências no mundo produzem efeitos na feitura do conhecimento que produzimos. Lelia Gonzalez (1980) já nos alertava muito antes que o lugar em que nos situamos determina nossa perspectiva sobre racismo e sexismo. Para a autora, "o racismo se constitui como a sintomática que caracteriza a neurose cultural brasileira" (GONZALEZ, 1980: 224). Não deixa de ser sintomático notarmos a ausência das reflexões propostas por Lélia Gonzalez no que se refere às discussões sobre produção de saber situado. Entendendo consciência como o lugar "do encobrimento, da alienação do esquecimento e até do saber" (GONZALEZ, 1980: 224) e memória como "o não-saber que conhece [...] o lugar da emergência da verdade" (GONZALEZ, 1980: 224) a autora afirma que a consciência atua por meio de um ocultamento da memória.

Podemos pensar que, em muitos momentos, o que fica ocultado nessa discussão sobre saberes situados é justamente os lugares de hegemonia que nos atravessam e que nos compõem. Jota Mombaça (2017) alega que a noção de saberes situados se infiltra na vida acadêmica muito mais como uma estratégia de hipervisibilizar as experiências subalternas do que de problematizar e nomear posições de poder:

Por isso o conceito de saberes situados acabou se limitando a reproduzir a hipervisibilidade da posição subalterna como objeto discursivo, sem criar condições para que, ao situar-se, os sujeitos posicionados em relação de privilégio perante a cisnormatividade, a heterossexualidade e a supremacia branca fossem capazes de perceber densamente a própria posição. (MOMBAÇA, 2017: 1)

Nesse sentido, é possível afirmar que os feminismos têm como proposta fundamental a transformação nas relações de gênero. Processo que passa necessariamente pela problematização das posições e relações de poder, de dominação e hegemonia e não apenas pelo acento nas experiências subalternas. Portanto, a proposta de desconstrução do androcentrismo e do positivismo pelos estudos feministas, principalmente a partir da Segunda Onda, instigou as mulheres a produzirem métodos que produzissem ressonâncias a essas vozes historicamente silenciadas, dando visibilidade e criando parâmetros para a promoção do 
enfrentamento ao patriarcado e a seus atravessamentos nas ciências (TEIXEIRA-FILHO, 2013). A narrativa de vida e o conhecimento situado foram percebidos como uma possibilidade de criar e consolidar um novo campo de investigação.

As abordagens narrativas, potencializadas pelas entrevistas, são bastante valorizadas nas investigações feministas principalmente pela possibilidade que abrem de enfocar "nos processos que condicionam a construção social dos fenômenos" (NEVES, 2012: 8). Para além disso, o compartilhamento de experiências por meio da narrativa de vida permite que les participantis de uma pesquisa possam refazer discursivamente seus percursos e produzir ou reformular os significados já atribuídos às suas experiências.

Uma das particularidades de metodologias que envolvem as produções narrativas tem a ver, como nos dizem Fernandéz e Martinéz (2014) com o fato de que pesquisadoris e participantis estão imersis no mesmo processo de investigação. Porém, essa imersão conjunta não significa afirmar a inexistência de relações de poder em jogo. Nós, enquanto pesquisadoris, temos interesses e objetivos específicos que nos outorgam uma maior capacidade de decisão no processo da pesquisa, razão pela qual não nos desprendemos totalmente do poder atribuído ao lugar de pesquisadoris. No entanto, o enfoque epistemológico, como afirmam as autoras, é crucial nesse processo. Balasch e Montenegro (2003) nos explicam que as narrativas, nesta perspectiva, não correspondem ao reflexo de um mundo interior, não evocam um sujeito, mas sim uma rede de relações. Nesse sentido, o processo metodológico é produtor de conhecimento, sempre em parceria com les participantis.

\section{Considerações finais}

Cabruja, Iñíguez e Vázquez (2000) apontam que enquanto práticas discursivas as narrativas de histórias de vida não se constituem apenas como encadeamento de palavras, frases e texto. As narrativas são elas próprias um conjunto de práticas e ações que constroem, atualizam e sustentam a realidade. Nesse sentido e por operar a partir do depoimento dus participantis da pesquisa essa metodologia atua diretamente sobre a realidade que se vai narrando, pois, o próprio relato se configura como uma ação sobre a realidade (NEVES, 2012). Corrobora com essa discussão a afirmação de Toledo (2013: 72) quando nos diz que

[...] produzimos nossas subjetividades e damos sentido a nossas vidas através das histórias que ouvimos, contamos e as experiências que compartilhamos com outros. Assim, ao contar, ouvir e recontar as histórias, as mesmas são (re)significadas, pois revividas pela própria expressão do discurso contado.

No mesmo sentido, Araújo e colaboradores (2016) asseveram que o trabalho com histórias de vida inevitavelmente produz uma intervenção e uma transformação conjunta com es participantis da pesquisa. Fato que se torna ainda mais evidente quando essa metodologia se volta às minorias sociais que invariavelmente são vítimas de diferentes tipos de violência (TOLEDO, 2013). Nesse sentido a possibilidade da narração de sua história de vida "confere às vítimas um sentido de luta contra a injustiça, uma vez que ao contar as suas vivências sentem-se envolvidas no processo de denúncia social do problema” (NEVES, 2012: 10).

Desse modo, é importante destacar que a participação em uma pesquisa não 
decorre simplesmente por meio da presença de pessoas a quem é "dado voz". Kastrup e Passos (2013) afirmam que para que uma participação se efetive é preciso que haja uma "experiência de pertencimento". Nesse sentido, é preciso haver desejo não somente de quem propõe a realização de uma pesquisa, mas também das pessoas que dela participam. Nesse sentido, torna-se fundamental estabelecermos uma crítica à ideia de que ume pesquisadore tenha o poder de dar voz às pessoas que irão compor uma pesquisa. Isto porque, como nos explicam Balasch e Montenegro (2003), esta ideia está pautada no pressuposto de que é a equipe investigadora que possui a legitimidade necessária para tanto. Amparadis ainda nas discussões promovidas por Balasch e Montenegro, acreditamos que as narrativas não podem ser vistas nem como um reflexo de um mundo interior e nem como simples reproduções de narrativas hegemônicas. Elas evocam não um sujeito, mas uma complexa rede de relações.

Assim, estamos sempre lidando com narrativas no que se refere ao âmbito da pesquisa (PASSOS e BARROS, 2009). Portanto, podemos considerar que há uma política de narratividade que diz respeito aos posicionamentos que inevitavelmente tomamos quando nos expressamos com relação ao mundo e a nós mesmos. Percebemos assim que a experiência é indissociável da produção de conhecimento já que viver diz respeito não a armazenar conhecimento, mas sim a produzi-lo ativamente, incorporando-o ao próprio ato de existir. Destarte, a narrativa é uma forma de organizar as experiências, que possuem uma natureza caótica e desordenada. Nesse sentido, para que possamos construir uma coerência precisamos organizar narrativamente nossas experiências (GONÇALVES, 2002).

A pesquisa narrativa, ao assumir a experiência como um conjunto complexo de relações e práticas discursivas e reconhecendo a relação indissociável entre pesquisadoris e participantis na produção de conhecimento, abre a possibilidade de questionarmos o pressuposto da produção de um saber que se dê independente da própria pessoa que o cria, que o produz. Dessa maneira, acreditamos que o conhecimento se produz tendo como fundamento as vivências, (des)conexões, afetamentos que marcam nossos (des)encontros com o outro, com o campo da pesquisa e com o próprio conhecimento. Nesse sentido, ele nunca é neutro e nem se refere a uma realidade independente, imparcial, já que a própria noção do que é real se faz nas relações que são travadas nos mais diversos contextos.

Recebido em 22 de janeiro de 2021.

Aprovado em 20 de abril de 2021. 


\section{Referências}

ARAÚJO, Patrícia; MARTINS, Emília; FERNANDES, Rosina; MENDES, Francisco; MAGALHÃES, Cátia. O Método das Histórias de Vida na Investigação Qualitativa em Psicologia. CIAIQ, 2: 588-595, 2016.

BALASCH, M.; MONTENEGRO, M. Una propuesta metodológica desde la epistemología de los conocimientos situados: las producciones narrativas. Encuentros en psicologia social, 1 (3): 44-48, 2003.

BENJAMIN, Walter. "O Narrador: considerações sobre a obra de Nikolai Leskov”. In: Magia e técnica, arte e política: ensaios sobre literatura e história da cultura. São Paulo: Brasiliense, 1994. pp. 197-221.

BIGLIA, Barbara; BONET-MARTÍ, Jordi. La construcción de narrativas como método de investigación psicosocial. Prácticas de escritura compartida. Forum Qualitative Social Research, 10 (1), 2009.

CABRUJA, Teresa; IÑ̃íGUEZ, Lupicinio; VÁZQUEZ, Félix. Como construimos el mundo: relativismo, espacios de relación y narratividad. Anàlisi, 25: 61-94. 2000.

DELEUZE, Gilles; GUATTARI, Félix. Kafka: por uma literatura menor. Rio de Janeiro: Imago, 1977.

FONTE, Carla. A narrativa no contexto da ciência psicológica sob o aspecto do processo de construção de significados. Psicologia: Teoria e Prática, 8 (2): 123131, 2006.

GONÇALVES, O. F. Viver narrativamente: a psicoterapia como adjetivação da experiência. Coimbra: Quarteto, 2002.

GRANATO, Tania Mara Marques; CORBERT, Elisa; AIELLO-VAISBERG, Tânia Maria José. Narrativa interativa e psicanálise. Psicologia em Estudo, 16 (1): 157163, 2011.

HARAWAY, D. Saberes localizados: a questão da ciência para o feminismo e o privilégio da perspectiva parcial. Cadernos Pagu, 5: 7-41, 1995.

HARDING, Sandra. “¿Existe un método feminista?” In: BARTA, Eli (coord.). Debates en torno a una metodología feminista. México DF: Universidad Autónoma Metropolitana-Unidad Xochimilco, 1987. pp. 5-34.

KASTRUP, V.; PASSOS, E. Cartografar é traçar um plano comum. Fractal, Rev. Psicol., 25 (2): 263-280, 2013.

LAU, Héliton Diego. "O uso da linguagem neutra como visibilidade e inclusão para pessoas trans não-binárias na língua portuguesa: a voz "del@s” ou “delxs"? Não! A voz "delus””. Anais do V Simpósio Internacional em Educação Sexual. Maringá: UEM, 2017.

NEVES, Sofia; NOGUEIRA, Conceição. A psicologia feminista e a violência contra as mulheres na intimidade: a (re)construção dos espaços terapêuticos. Psicologia e Sociedade, 15 (2): 43-64, 2003.

OLIVEIRA, João Manuel de; AMÂNCIO, Lígia. Teorias feministas e representações sociais: desafios dos conhecimentos situados para a psicologia social” Estudos Feministas, 14 (3): 597, 2006. 
SILVA, Aline Pacheco; BARROS, Carolyne Reis; NOGUEIRA, Maria Luísa Magalhães; BARROS, Vanessa Andrade de. "Conte-me sua história": Reflexões sobre o método de história de vida. Mosaico: Estudos em Psicologia, Belo Horizonte, 1 (1): 25-35, 2007.

SCOTT, Joan. A invisibilidade da experiência. Revista Projeto História, 16: 297325, 1998.

TEIXEIRA-FILHO, Fernando Silva. Psicologia e Teoria Queer: das identidades aos devires. Tese de Livre Docência, Psicologia, UNESP, 2013.

TELLES, João A. A trajetória narrativa: história sobre a formação do professor de línguas e sua prática pedagógica. Trabalhos em Linguística Aplicada, 34: 7992, 1999.

TOLEDO, Lívia G. "Será que eu tô gostando de mulher?”: tecnologias de normatização e exclusão da dissidência erótica feminina no interior paulista. Tese de Doutorado, Psicologia, UNESP, 2013. 

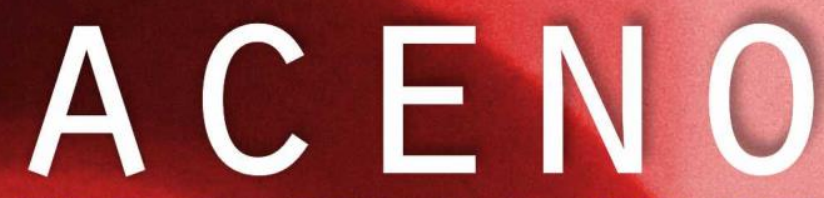

$\sum$

REVISTA DE ANTROPOLOGIA DO CENTRO I SSN: $2358-5587$

$\propto$

(1)

$<$

Revista quadrimestral $\vdash$ editada pelo Programa u de Pós-Graduação em $\mapsto \quad$ Antropologia Social da 인, desde 2014. z ACENO, REVISTADEANTROPOLOG I A 